\title{
The Oldest Old and the Risk of Social Exclusion
}

\author{
Wesley Key* and Martin Culliney** \\ *School of Social and Political Sciences, University of Lincoln \\ E-mail:wkey@lincoln.ac.uk \\ ** Centre for Education and Inclusion Research, Sheffield Hallam University \\ E-mail: m.culliney@shu.ac.uk
}

This article examines whether people aged eighty-five-and-over, referred to throughout as 'The Oldest Old', are more likely to suffer from social exclusion than people aged sixty-five to eighty-four. Social Exclusion is defined according to the four dimensions identified in the 1999 Poverty and Social Exclusion Survey. Using data from Understanding Society, the analysis finds that the Oldest Old have a higher likelihood of experiencing social exclusion than people aged sixty-five to eighty-four. These findings illustrate the risks facing the Oldest Old, and highlight the policy challenges presented by ageing western populations.

Keywords: Age, disability, Oldest Old, service provision, social exclusion.

\section{Introduction}

The growing number of people aged eighty-five-and-over, known throughout as the Oldest Old, is one of the key demographic trends of the twenty-first century to date. The ONS estimates that a person aged sixty-five in 2014 will live to be eighty-five, given current age-specific mortality rates (see Public Health England, 2016). In the United Kingdom, there will be 3.2 million people aged eighty-five-and-over by 2039: 4.4 per cent of the population, an increase from 2.3 per cent in 2014 (ONS, 2015: 6). In England and Wales, the number of people aged eighty-five-and-over rose from 1.01 million to 1.25 million between the 2001 and 2011 Censuses, a faster rate of growth than for the sixty-five to seventy-four or seventy-five to eighty-four age groups (ONS, 2013). It is projected that this pattern will continue, with advances in health and technology extending the life of western populations further still.

Whilst increasing life expectancy is a positive development, it has policy implications in terms of living arrangements, health, quality of life and social participation (House of Lords, 2013), and has been labelled a 'demographic time bomb (Gilleard and Higgs, 2010). The Oldest Old are more likely to have support needs than younger people, as the number of older people with disabilities who do not have a spouse or partner is rising (Pickard, 2015). Incidences of conditions that are more common in old age, such as dementia, cancer and stroke, are increasing (Her Majesty's Government, 2013), as more people are living to be aged eighty-five-and-over. The average cost of health services for someone aged eighty-five-and-over is three times higher than for an individual aged sixty-five to seventy-four (Cracknell, 2010).

The challenges presented by this demographic trend are profound. Despite this, little academic research has specifically examined the over-eighty-fives. Some studies (Barnes et al., 2006; Kneale, 2012) have implicitly suggested that the risk of social 
exclusion is greater at age eighty-five-plus than for people aged sixty-five to eightyfour, yet these analyses were restricted by small samples. This article makes an important contribution to the literature by examining the likelihood of people aged eighty-five-andover experiencing social exclusion compared to their younger counterparts. It addresses the following question: How does the likelihood of social exclusion differ between people aged sixty-five to eighty-four and people aged eighty-five-and-over?

We begin with an overview of the concept of social exclusion. The term has been used rather loosely at times and there have been charges of conceptual vagueness, which have not been entirely unjustified. We put forward a rigorous conceptualisation, based on established empirical and theoretical accounts, to inform our operationalisation of social exclusion. Next, relevant literature on the Oldest Old is discussed, with an emphasis on social exclusion. Data and methods are then detailed, and we specify the indicators of social exclusion chosen. Descriptive statistics are then presented, followed by the main data analysis. The risk of social exclusion, in terms of our chosen three indicators, is found to be greater for people aged eighty-five-and-over. In the concluding section, we reflect on the results and discuss their significance to policy-makers.

\section{Conceptualising social exclusion}

The origins of the term 'social exclusion' stem from 'the synthesis of social Catholicism and republicanism in contemporary France' (Byrne, 1999: 8). European interest in the concept began in 1974 when René Lenoir, Secretary of State for Social Action in a French Gaullist government, first popularised the term, which was used by the French socialist governments of the 1980s in relation to the long-term unemployed. In 1989, the European Commission was called upon by the Council of Ministers to study the measures being taken to tackle social exclusion, and it established the European Observatory to combat the problem. The European Union subsequently placed poverty and social exclusion at the heart of its social policy agenda for the 2000 Lisbon summit, requiring member states to produce biennial national action plans (Levitas et al., 2007). An edited collection entitled 'Beyond the Threshold' (Room, 1995) reflected on the work of the Observatory, arguing that a 'paradigm shift' had taken place with static accounts of states of poverty and disadvantage succeeded by dynamic analyses of ongoing, multi-dimensional processes of social exclusion. Attempts to define social exclusion typically 'distinguish it from poverty precisely on the basis of its multi-dimensional, relational and dynamic character. Poverty, by contrast, is portrayed as a distributive concept, concerned with resources, or simply low income' (Levitas et al., 2007: 26). This notion of social exclusion as a protean concept informs the empirical element of our research.

The concept of social exclusion stems from a Durkheimian conception of solidarity and integration into social space (Veit-Wilson, 2002) where society is seen as a status hierarchy, bound together by sets of mutual rights and obligations rooted in a broader moral order. Social exclusion has been seen as the antithesis of citizenship, and as a process where a minority are denied the citizenship rights held by the 'included' majority (Lister, 1997), leaving them detached from the mainstream. It is the end product of the failure of institutional systems that determine an individual's integration within society (Commins, 1993; Walker, 1997), which can involve a loss of access to the life chances that affect one's ability to participate in society (Patsios, 2000). Levitas et al. see it as a complex process involving 'the lack, or denial, of resources, rights, goods and services, 
and the inability to participate in the normal relationships and activities, available to the majority of people in a society, whether in economic, social, cultural or political arenas', observing that 'it affects both the quality of life of individuals and the equity and cohesion of society as a whole' (2007: 25). This multi-dimensionality is a crucial characteristic of social exclusion.

In Britain, social exclusion was a policy priority of the Blair administrations (19972007). Motivated by the moralistic notions of social integration through labour market participation (Levitas, 1998) that echoed the US 'workfare' schemes of the Clinton era, Blair's New Labour government launched the Social Exclusion Unit (SEU) in December 1997 to provide a cross-departmental approach to the complex problems of specific disadvantaged groups. It focused initially upon rough sleepers, school truants, pregnant teenagers and young people not in education, employment or training (Levitas et al., 2007). Until June 2006, when its work was subsumed into that of a Cabinet Office Task Force, the SEU coordinated government policy towards geographically concentrated disadvantage, targeting 'whole communities deprived of proper access to transport, to healthcare and financial services' (Harman, 1997).

Within the operational framework of the SEU, the dominant discourse of inclusionthrough-paid employment overlooked unpaid care work (Millar, 2003), much of which is done by older people. Moreover, the early work of the SEU did not address the social processes that exclude older, retired people (Walker, 2000). Instead, policy was aimed toward Neighbourhood Renewal and the aforementioned specific disadvantaged groups, with little attention given to social exclusion in later life until SEU publications on 'Excluded Older People' (Social Exclusion Unit, 2005, 2006). The term 'social exclusion' subsequently lost prominence within government Social Policy rhetoric during the premierships of Gordon Brown and David Cameron, with the Cameron-led governments of 2010 instead promoting personal responsibility to obtain paid work as the best route out of poverty. This narrative remains prevalent in government discourse today.

\section{Researching social exclusion in later life}

Across the developed world, the significant rise in the population aged eighty-five-andover has led to older people sometimes being differentiated into 'young old' and 'old old' categories. The Oldest Old have been defined as aged seventy-five-and-over (Poon and Cohen-Mansfield 2011), eighty-and-over (Gjonca et al. 2010); ninety-and-over (Dini and Goldring, 2008), or the age at which 50 per cent of the birth cohort are no longer alive (Baltes and Smith, 2003). We use age eighty-five as the lower limit for classification as 'Oldest Old', in line with the recent announcement that people currently aged sixtyfive can expect to live until eighty-five (Public Health England, 2016), and several other studies (Tomassini, 2005, 2006; Age UK, 2013; ILC-UK, 2013).

What we term the 'Oldest Old' period of life ordinarily entails declining control over decision-making and increased dependence upon other people (Gilleard and Higgs, 2010, 2011). Changes to relationships (loss of friends and family, more contact with care staff and medical professionals) affect capacity to maintain a social life, as does worsening physical health (Lloyd et al., 2014). Morbidity and mortality are increasingly concentrated among the oldest age groups, with later life characterised by deterioration in functional health, memory and mobility, alongside the impact of bereavement (Heikkinnen, 2000). Although some evidence suggests differences between birth cohorts in the prevalence of 
mental illness diagnoses and conditions such as hypertension and diabetes (Rice et al., 2010), this does not include individuals aged eighty-five and above.

Kneale (2012), using English Longitudinal Study of Ageing (ELSA) Waves 1 and 4, discovered a higher risk of social exclusion for people aged eight-and-over than those aged fifty to seventy-nine, finding that having no partner or children made older people more likely to be excluded from social relationships, and at greatest risk of overall exclusion. Scharf et al. (2002) suggested that various processes such as long-term poverty, poor health and biographical factors such as widowhood or divorce can contribute to exclusion in later life. Barnes et al. (2006) used data from ELSA Wave 1 and found that people aged eighty-and-over were at greater risk of exclusion from social relationships, basic services and material goods than those aged fifty to seventy-nine, due to lower incomes, being more likely to live alone, and poorer physical and mental health. These conclusions imply that the effect of age can be explained away through reference to these other factors. This article presents analysis that disputes this, arguing that social exclusion among the Oldest Old is more likely even when other important predictors are taken into account.

\section{Operationalising social exclusion}

The interaction between different dimensions of social exclusion has been examined through secondary analysis of the British Household Panel Survey data (Burchardt, 2000; Burchardt et al., 2002), and the Millennium Survey of Poverty and Social Exclusion in Britain (Gordon et al., 2000). The 1999 Poverty and Social Exclusion (PSE) Survey measured four dimensions of social exclusion within the UK: exclusion from adequate income or resources; labour market exclusion; service exclusion; exclusion from social relations (Gordon et al., 2000). Service exclusion and exclusion from social relations are especially relevant to older people (Patsios, 2000).

This article builds upon the conceptual foundations of Patsios (2000). As it is concerned with older people, particularly those aged eighty-five-and-over, we focus on two of the four facets of social exclusion most relevant to this age group: exclusion from services, and exclusion from social relations. Income and resources can be difficult to measure accurately, especially for older people, whose lower housing costs make it hard to gauge the financial security and material comfort in which they live. The economic circumstances faced by the Oldest Old are undoubtedly of interest to researchers, but the complexity inherent in studying this puts it beyond the scope of this article. The Oldest Old are also less likely to be in paid employment, which makes it less meaningful to consider whether they suffer from labour market exclusion (see Patsios, 2000: 30). Thus, we focus here on the two remaining dimensions, service exclusion, and exclusion from social relations.

Exclusion from services. Lack of access to transport is a significant potential cause of social exclusion (Shergold and Parkhurst, 2012), and exclusion from basic services stems from a lack of access to adequate public and private transport (Kenyon et al., 2003). Access to services is highly dependent on having use of a car, with lift-giving networks helping to combat mobility-related exclusion, particularly amongst the Oldest Old (Shergold and Parkhurst, 2012). Lack of a household car affects 25.2 per cent of people aged fiftyplus, rising to 55.3 per cent of people aged eighty-five-plus (ONS, 2003). People aged 
eighty-five-and-over have lower levels of access to car transport, public transport, mobile phones and the internet than younger people (Serra et al., 2011).

Health problems and disabilities can force older people to reduce or cease their driving and their use of public transport, making it harder to access service provision. The prevalence of physical disabilities that make it difficult to use public transport is highest among people aged eighty-five-and-over (DTLR, 2001). Aside from being less likely than younger people to hold a driving licence, own a car or use public transport, the Oldest Old are more likely to distinguish between 'essential' (such as medical appointments) and 'discretionary' travel (Davey, 2007), typically focusing their car use on the former, and reducing, or ceasing, the latter.

This evidence leads us to predict that the Oldest Old are more likely to report being excluded from services than those aged sixty-five to eighty-four [Hypothesis $1(\mathrm{H} 1)$ ]. The limited literature leading us to formulate this hypothesis indicates that poor health or issues surrounding transport may be behind this variation. To demonstrate that the effect of age remains significant when controlling for transport availability and health, we will include indicators of these concepts in our models as predictors.

Exclusion from social relations. There is mixed evidence on the link between social contact and advancing age. Involvement in church/religious groups is higher among people aged eighty-five-plus than people aged sixty-five to eighty-four (Gjonca et al., 2010), which could be interpreted as a sign of continued social activity. On the other hand, participation in voluntary work drops from 22 per cent of those aged sixty-five-sixty-nine to 7 per cent of those aged eighty-plus (Askham, 1992); one could see this as a proxy for decreasing social interaction. People aged eighty-five-and-over are less likely to have weekly contact with friends and family (Victor et al., 2003), and face a higher risk of isolation and loneliness than people aged sixty-five to eighty-four (Age UK, 2013). On balance, this would suggest that it is likelier that the Oldest Old face exclusion from social contact more than their younger counterparts.

Many of the Oldest Old are childless, have no living siblings, and are separated, bereaved or have never married, shrinking the pool of people who could potentially become informal carers (Tomassini, 2005). Nevertheless, the number of older people with disabilities receiving care from a spouse/partner is still projected to increase by over 90 per cent during 2007-32 (Pickard, 2015). Demand for unpaid care from adult children for older people with disabilities in England is expected to exceed supply by 2017 (House of Lords, 2013), and a projected rise in childless older people in Britain, coupled with rising economic activity rates for middle-aged women (Pickard et al., 2007), may lead to less available support from younger family members. Again, this evidence points to an increased likelihood of social exclusion among the Oldest Old.

Tomaszewski and Barnes (2008) found that older people (aged eighty-plus in their study) were at greater risk of social detachment but that the effect of age disappeared when family type was controlled for, partly because the oldest people are most likely to live alone. However, the evidence of the Oldest Old being at greater risk of social exclusion now appears strong enough to predict that the effect of age will persist even when controlling for other key variables, which are specified in the following section. Hence, we hypothesise that the Oldest Old are at greater risk of exclusion from social contact than respondents aged sixty-five to eighty-four [Hypothesis $2(\mathrm{H} 2)$ ]. 


\section{Data and methods}

The main purpose of this article is to compare the likelihood of suffering social exclusion for people aged eighty-five-and-over with people aged sixty-five to eighty-four. The Understanding Society Wave 3 dataset has been chosen as it contains enough cases to conduct this comparison robustly, and also includes variables representing the two social exclusion dimensions of greatest interest here. Understanding Society is a longitudinal panel study sampling 40,000 households in England, Wales, Scotland and Northern Ireland. The survey replaced the British Household Panel Survey (BHPS), which ran from 1991 until 2008/9. Some BHPS respondents continued to participate in Understanding Society, for which the first wave of data collection took place in 2010.

We use data from Wave 3, the most recent available at the time of writing. Wave 3 of Understanding Society contained 49,739 adult responses, of which 10,069 were from people aged sixty-five-and-over, with 848 of these being aged eighty-five-andover. This subsample of respondents aged sixty-five-and-over forms the basis for the analyses presented in the following section. Fifty-four per cent of the over-sixty-fives in Understanding Society Wave 3 were female, broadly consistent with wider population estimates. We follow user guidance by using the cross-sectional weight 'c_indinub_xw' (Understanding Society, Wave 3) for all descriptive statistics.

Our analysis focuses on two outcomes: exclusion from services and exclusion from social contact. Understanding Society asks respondents: 'Are you able to access all services such as healthcare, food shops or learning facilities when you need to?' (variable name: c_servacc) (Understanding Society, Wave 3). This is self-reported, and we take it as a valid indicator of the underlying concept of exclusion from services. If individuals feel unable to access services when needed, it seems fair to say that they are excluded in this respect. This is presented as a dichotomous variable, with respondents simply answering yes or no. We treat this as an outcome in a logistic regression model.

The second dimension of social exclusion to be explored concerns social relations. For this, there are two variables in the dataset that we treat as outcomes in our multivariate modelling. Firstly, Understanding Society asks if each respondent 'visits family when needs to' (variable name: c_visfam) (Understanding Society, Wave 3). This is a categorical variable with responses given on a scale from one (very difficult) to five (very easy). There is also a sixth category, for respondents who spontaneously reply that they have no family. For the purpose of our analysis, we recode this variable by combining 'very difficult' and 'difficult' into one category, to represent difficulty visiting family as an indicator of exclusion from social relations. We then create a second category from all other valid responses, for individuals who do not have difficulty in visiting family. Respondents with no family are excluded from this analysis. We then treat this new dichotomous variable as an outcome in a logistic regression model, again including all of the predictors listed above, to determine the effect of age on the likelihood of experiencing this dimension of social exclusion.

Respondents are also asked if they 'go out socially' (c_visfrnds) (Understanding Society, Wave 3). One might expect that an individual's capacity to lead an active social life declines with advancing years, typically due to worsening health, or other reasons such as having no friends to go out with. It is clear that this measure of social interaction corresponds with the concept of exclusion from social contact. For this reason, we include 
Table 1. Predictor variables by age category

\begin{tabular}{|c|c|c|c|c|}
\hline Predictor variables & Aged 65-84 & $85+$ & Total & $\chi^{2}$ \\
\hline Male \% & 47.1 & 41.0 & 46.4 & \\
\hline Female \% & 52.9 & 59.0 & 53.6 & \\
\hline Unweighted N & 9,221 & 848 & 10,069 & $13.253^{* * *}$ \\
\hline Urban \% & 71.1 & 73.0 & 71.3 & \\
\hline Rural \% & 28.9 & 27.0 & 28.7 & \\
\hline Unweighted $\mathrm{N}$ & 9,221 & 847 & 10,068 & 1.676 \\
\hline Single in $\mathrm{HH} \%$ & 64.8 & 28.8 & 61.0 & \\
\hline Not single in $\mathrm{HH} \%$ & 35.2 & 71.2 & 39.0 & \\
\hline Unweighted N & 9,221 & 848 & 10,069 & $481.528^{* * *}$ \\
\hline Has use of car or van \% & 91.6 & 72.4 & 90.4 & \\
\hline Has no use of car or van $\%$ & 8.4 & 27.6 & 9.6 & \\
\hline Unweighted $\mathrm{N}$ & 6,690 & 350 & 7,040 & $164.363^{* * *}$ \\
\hline Yes, limited a lot \% & 15.9 & 39.3 & 17.8 & \\
\hline Yes, limited a little \% & 29.7 & 34.2 & 30.1 & \\
\hline No, not limited at all \% & 54. & 26.6 & 52.1 & \\
\hline Unweighted $\mathrm{N}$ & 7,240 & 503 & 7,743 & $273.991^{\text {*** }}$ \\
\hline
\end{tabular}

Source: Understanding Society Wave 3, all respondents aged sixty-five and above.

it in our multivariate modelling. Along with the difficulty that someone has in visiting family when they need to, this represents exclusion from social contact.

\section{Study limitations}

Consideration of the financial circumstances faced by the Oldest Old was beyond the scope of the current study due to the complexity involved in looking at the economic position of older members of society, who are unlikely to be in paid employment but more likely to have assets such as property and pensions. A further difficulty would be in deciding whether to treat financial wellbeing as a predictor of the two dimensions of social exclusion examined here, or as an outcome in itself as in Patsios (2000). There is a case for investigating both angles, so broadening the enquiry to encompass a financial dimension of social exclusion would be a worthy extension to this article.

While the sample size has enabled us to conduct the analysis required to answer the research questions and confirm the hypotheses, it must be noted that the approach taken has been cross-sectional. This provides an insightful snapshot into the circumstances of the Oldest Old, about whom empirical evidence has been relatively scarce, yet the longitudinal data structure of Understanding Society holds great promise for researchers as the demographic composition of society continues to change. Unfortunately, it was not possible to pursue this due to space constraints, but the longitudinal design of this survey should be exploited in further academic enquiry.

\section{Descriptive statistics}

This section presents descriptive statistics on each of the key variables (see Table 1). The sub-sample of respondents aged sixty-five-and-over contains a slightly higher proportion of females overall (53.6 per cent), with the proportion of males declining from 47.1 
per cent among the sixty-five to eighty-four age range to 41 per cent of those aged eighty-five-and-over. This is unsurprising given that women have longer life expectancy than men (see Collins et al., 1997; Del Bono et al., 2007). Of the sub-sample aged sixty-five-and-over, 71 per cent live in urban areas, rising to 73 per cent of the Oldest Old. Nationally, around one in five people are rural residents, but as it is widely acknowledged that the rural population is older, our subsample figures are broadly in line with expectations. The exclusion from services and social relations of people living in rural Britain has been expounded elsewhere (Key, 2014), so we are interested in the association between geographical location and social exclusion.

A far greater proportion of the Oldest Old report being the only member of their household than the sixty-five to eighty-four age group. This is consistent with expectations as there is a greater chance that the Oldest Old will have been widowed. It is less likely that individuals of this age will form new intimate relationships. One can reasonably assume that living alone increases the difficulty of accessing services, without the support of a partner to assist with transportation for example, and it is also plausible to assume that residing alone reduces opportunities for social interaction with others (see Barnes et al. 2006; Tomaszewski and Barnes, 2008), so we include this variable in our modelling.

Another variable that we treat as a predictor in our modelling is whether the respondent has use of a car or van. While only 8 per cent of those in the sixty-five to eighty-four age range report having no access to a motor vehicle, this rises to 28 per cent for the Oldest Old. We consider it less likely that individuals having private transportation at their disposal will suffer from social exclusion, and this variable is therefore entered into our models as a predictor.

The final predictor variable of interest is health. We use a self-reported measure of whether the respondent believes that health limits their ability to engage in moderate activity (see note 1). It is expected that individuals whose health limits moderate activities find it more difficult to access services and experience less social contact than people reporting good health. However, we hypothesise that the Oldest Old are more likely to be socially excluded on both dimensions of the concept under consideration in this article. We expect this finding to persist even when controlling for respondent health and all other predictors discussed thus far.

As mentioned, we are looking at three outcome variables in this investigation. These are indicators of the underlying concept of social exclusion, specifically exclusion from services and social contact. Table 2 shows that accessing services is more problematic for the Oldest Old, with 16 per cent of participants aged eighty-five-and-over reporting that they cannot access services, compared to only 4 per cent of younger counterparts. There is also a pronounced age difference when looking at the two indicators of social contact. While only 17 per cent of respondents aged sixty-five to eighty-four do not go out socially, this increases to 46 per cent for the eighty-five-and-over category. Similarly, 19 per cent of the Oldest Old report that it is very difficult to visit family when they need to, compared to 9 per cent of those aged sixty-five to eighty-four. It is also noteworthy that the Oldest Old are more likely to report having no family. We recode this variable into a dichotomous measure in the logistic regression model that follows in the next section. As mentioned above, we treat individuals stating that they find visiting family either 'very difficult' or 'difficult' as being socially excluded (1). All other responses to this question are treated as not socially excluded (0). 
Table 2. Outcome variables by age category

\begin{tabular}{llccc}
\hline \hline Outcome variables & Aged 65-84 & $85+$ & Total & \multirow{2}{*}{$\chi^{2}$} \\
\hline Able to access services when need to \% & 95.8 & 84.1 & 94.6 & \\
Not able to access services \% & 4.2 & 15.9 & 5.4 & \\
Unweighted N & 8,824 & 767 & 9,591 & $233.017^{* * *}$ \\
Goes out socially \% & 82.9 & 54.3 & 79.9 & \\
Does not go out socially \% & 17.1 & 45.7 & 20.1 & \\
Unweighted N & 8,825 & 769 & 9,594 & \multirow{2}{*}{$451.796^{* * *}$} \\
Visits family when need to & & & & \\
Very difficult \% & 6.5 & 24.7 & 8.4 & \\
Difficult \% & 9.0 & 19.2 & 10.1 & \\
Neither difficult nor easy \% & 13.4 & 13.7 & 13.4 & \\
Easy \% & 40.9 & 27.7 & 39.5 & \\
Very easy \% & 28.4 & 11.2 & 26.6 & \\
Spontaneous: has no family & 1.8 & 3.6 & 2.0 & \\
Unweighted N & 8,800 & 766 & 9,566 & $585.531^{* * * *}$ \\
\hline \hline
\end{tabular}

Source: Understanding Society Wave 3, all respondents aged sixty-five and above.

\section{Multivariate modelling}

Before presenting the multivariate models that form the main empirical contribution of this piece, a further point arising from the descriptive statistics must be made. There is item non-response for several of the predictor and outcome variables. Proceeding with the analysis leads to the models being estimated with 43 per cent of cases excluded. Clearly, this level of missing data poses the risk of bias. As seen in Tables 1 and 2, the missing values are distributed across many variables. We have dealt with this problem by using multiple imputation to provide estimates of the missing values through regression procedures. This technique replaces values missing through item non-response with values estimated according to other respondent characteristics. The approach is preferable to replacing the missing values with the mean, or the alternative of dropping cases on a list-wise basis, which would substantially reduce the sample size and potentially distort the findings. Hence, multiple imputation was considered the best option. All results presented are from five pooled datasets. The original data were dropped as they contained missing values. Thus, the pooled data used contain the full 10,069 cases.

Table 3 displays the results of a logistic regression model with 'able to access services?' as the outcome variable. Model 1 enters three predictors, gender, age and rural/urban location. Respondents aged eighty-five-and-over are significantly less likely to be able to access services compared to the reference category of respondents aged sixty-five to eighty-four $(\operatorname{Exp}(B)=0.224)$. This age effect controls for gender and location. Women are more likely to be unable to access services than men $(\operatorname{Exp}(B)=0.524)$, and there is no significant effect for location.

Model 2 shows that respondents living with a spouse or partner are more likely to be able to access services than those living alone $(\operatorname{Exp}(B)=1.817)$. The effect of age remains significant, although it is slightly smaller once cohabitating status is controlled for $(\operatorname{Exp}(B)$ $=0.273$ ). From this, there seems to be an age effect on the likelihood of being socially 
Table 3. Logistic regression model, outcome: is/not (1/0) able to access services

\begin{tabular}{|c|c|c|c|c|c|c|c|c|c|}
\hline \multirow[b]{2}{*}{ C_SERVACC } & \multicolumn{3}{|c|}{ Model 1} & \multicolumn{3}{|c|}{ Model 2} & \multicolumn{3}{|c|}{ Model 3} \\
\hline & S.E. & Sig. & $\operatorname{Exp}(B)$ & S.E. & Sig. & $\operatorname{Exp}(B)$ & S.E. & Sig. & $\operatorname{Exp}(B)$ \\
\hline Female (ref. male) & 0.100 & 0.000 & 0.524 & 0.104 & 0.000 & 0.605 & 0.106 & 0.000 & 0.658 \\
\hline Aged 85+ (ref. aged under 85) & 0.111 & 0.000 & 0.224 & 0.115 & 0.000 & 0.273 & 0.124 & 0.000 & 0.415 \\
\hline Rural (ref. urban) & 0.101 & 0.760 & 0.970 & 0.102 & 0.593 & 0.947 & 0.105 & 0.111 & 0.846 \\
\hline Lives with spouse/ partner (ref. lives alone) & & & & 0.102 & 0.000 & 1.817 & 0.106 & 0.000 & 1.511 \\
\hline No use of car (has use) & & & & & & & 0.150 & 0.000 & 0.483 \\
\hline \multicolumn{10}{|l|}{ Health limits moderate activities (ref. does not limit) } \\
\hline Yes, limited a lot & & & & & & & 0.155 & 0.000 & 0.203 \\
\hline Yes, limited a little & & & & & & & 0.182 & 0.008 & 0.576 \\
\hline Constant & 0.093 & 0.000 & 36.215 & 0.113 & 0.000 & 23.821 & 0.170 & 0.000 & 53.595 \\
\hline-2 Log likelihood & & 3771.793 & & & 3738.482 & & & 3507.83 & \\
\hline
\end{tabular}

Source: Understanding Society Wave 3, all respondents aged sixty-five and above. 
excluded with regard to service access that remains significant after controlling for living arrangements.

Model 3 adds two further predictors into the analysis. Firstly, individuals with no use of a car are less likely to be able to access services $(\operatorname{Exp}(B)=.483)$. Secondly, the extent to which health limits moderate activity appears to have a significant effect. Respondents who state that their health limits moderate activity 'a lot' are far less likely to report being able to access services than those for whom health does not limit moderate activity $(\operatorname{Exp}(B)=.203)$. Furthermore, the Oldest Old remain less likely to be able to access services than their younger counterparts, even with health and use of a private vehicle taken into account. This finding offers support for our first hypothesis, suggesting that the Oldest Old are at greater risk of social exclusion in terms of ability to access services. Having established that there is a clear age effect in relation to this dimension of social exclusion, the analysis now turns to social contact.

Table 4 presents a logistic regression model analysing the first of our two indicators of social contact, whether the respondent can visit family members when they need to. Model 1 shows that the odds of the Oldest Old having difficulty visiting relatives are far greater than for those aged sixty-five to eighty-four $(\operatorname{Exp}(B)=4.146)$. Females are also more likely than males to report difficulty visiting family when they need to $(\operatorname{Exp}(B)=$ 1.376). There is no significant variation regarding rural/urban location. Model 2 introduces cohabitation status into the analysis. Unsurprisingly, people who live alone report having more difficulty visiting relatives $(\operatorname{Exp}(B)=0.479)$. It is important to note that the effect of age remains significant when this additional predictor is entered into the model $(\operatorname{Exp}(B)=$ 3.311 ), with the Oldest Old far more likely to report having difficulty in this respect than younger respondents.

Model 3 then adds two further predictors, access to a car, and health. Participants without access to a private motor vehicle are more likely to have difficulty visiting relatives $(\operatorname{Exp}(B)=1.696)$, and those whose health limits moderate activity are more likely to have this difficulty $(\operatorname{Exp}(B)=2.796)$ compared with reporting no such health limitations. The age effect remains significant once these extra variables are included in the regression $(\operatorname{Exp}(B)=2.556, p<0.001)$. This suggests that among the Oldest Old, there is a greater risk of being excluded from social contact as measured by the indicator used here, even when living alone, car use, location and health are taken into account. While this finding offers support for our second hypothesis, it must be recognised that family contact is not the only social interaction that can be of importance, so we look at one more indicator of social relations.

The final indicator of social exclusion (and more specifically, social contact) to be examined is whether the respondent goes out socially. Table 5 displays the results from a logistic regression model with this binary variable as the outcome. The same predictors used in the previous models are again used here. Model 1 shows that the Oldest Old are significantly less likely to report that they go out socially than younger respondents $(\operatorname{Exp}(B)=.244, p<.001)$. Females are also less likely than males to go out with friends $(\operatorname{Exp}(B)=.873, p<.05)$, and, perhaps surprisingly, rural respondents are more likely to go out than urban residents $(\operatorname{Exp}(B)=1.224, \mathrm{p}<.01)$.

The results from Model 2 show that respondents living with a spouse or a partner are more likely to go out socially $(\operatorname{Exp}(B)=1.548)$. This illustrates how having a partner can facilitate further social contact, and also provides evidence that living alone increases the risk of an individual being socially excluded with regard to the social contact dimension. 
Table 4. Logistic regression model, outcome: does/not (1/0) have difficulty visiting family when needs to

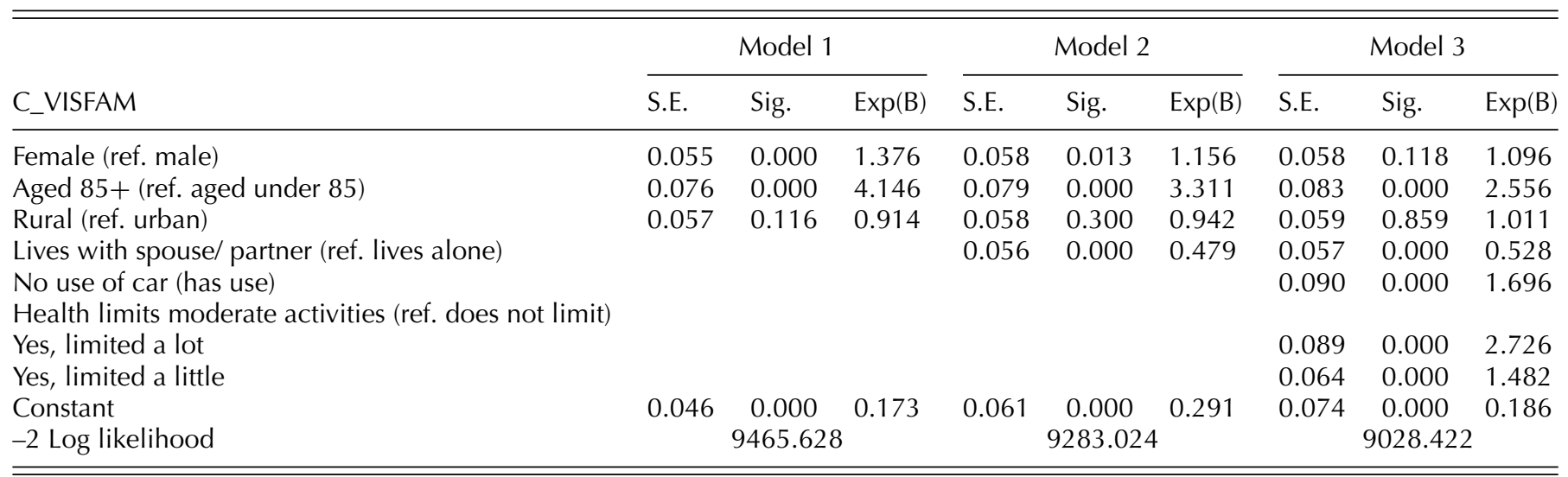

Source: Understanding Society Wave 3, all respondents aged sixty-five and above except those with no family. 
Table 5. Logistic regression model, outcome: does/not (1/0) go out socially

\begin{tabular}{|c|c|c|c|c|c|c|c|c|c|}
\hline \multirow[b]{2}{*}{ C_VISFRNDS } & \multicolumn{3}{|c|}{ Model 1} & \multicolumn{3}{|c|}{ Model 2} & \multicolumn{3}{|c|}{ Model 3} \\
\hline & S.E. & Sig. & $\operatorname{Exp}(B)$ & S.E. & Sig. & $\operatorname{Exp}(B)$ & S.E. & Sig. & $\operatorname{Exp}(B)$ \\
\hline Female (ref. male) & 0.053 & 0.010 & 0.873 & 0.054 & 0.551 & 0.968 & 0.056 & 0.562 & 1.033 \\
\hline Aged 85+ (ref. aged under 85) & 0.084 & 0.000 & 0.244 & 0.087 & 0.000 & 0.281 & 0.095 & 0.000 & 0.379 \\
\hline Rural (ref. urban) & 0.060 & 0.001 & 1.224 & 0.061 & 0.002 & 1.203 & 0.061 & 0.092 & 1.108 \\
\hline Lives with spouse/ partner (ref. lives alone) & & & & 0.056 & 0.000 & 1.548 & 0.058 & 0.000 & 1.357 \\
\hline No use of car (has use) & & & & & & & 0.089 & 0.000 & 0.495 \\
\hline \multicolumn{10}{|l|}{ Health limits moderate activities (ref. does not limit) } \\
\hline Yes, limited a lot & & & & & & & 0.072 & 0.000 & 0.327 \\
\hline Yes, limited a little & & & & & & & 0.077 & 0.000 & 0.622 \\
\hline Constant & 0.044 & 0.000 & 5.083 & 0.059 & 0.000 & 3.701 & 0.073 & 0.000 & 6.388 \\
\hline-2 Log likelihood & & 9465.628 & & & 9283.024 & & & 9028.422 & \\
\hline
\end{tabular}

Source: Understanding Society Wave 3, all respondents aged sixty-five and above. 
Once this new variable on living arrangements is entered into the model, the gender effect becomes insignificant but rural location remains a significant predictor $(\operatorname{Exp}(B)=1.203$, $\mathrm{p}<.01)$. The Oldest Old also remain less likely to go out socially $(\operatorname{Exp}(B)=.281, p<.000)$ even when cohabiting status is taken into account, suggesting that this age group is at greater risk of social exclusion irrespective of whether they live alone.

Model 3 once again introduces car use and satisfaction with health into the regression as predictors. Individuals with no access to a vehicle are less likely to go out socially $(\operatorname{Exp}(B)=.495, \mathrm{p}<.001)$ which demonstrates the difficulties that people can have in maintaining social contacts without having transport at their disposal. Model 3 also shows that respondents reporting that their health limits moderate activity 'a lot' are less likely to go out socially $(\operatorname{Exp}(B)=.327, p>.001)$, in line with expectations. It should also be noted that the age effect remains significant once these two predictors are included in the model, with the Oldest Old still less likely to go out with friends than younger counterparts $(\operatorname{Exp}(B)=.316, p<.001)$. This provides further support for our second hypothesis, which is that the Oldest Old are at greater risk from social exclusion in terms of social contact. That the variation remains significant once health, transport access and living situation are controlled for suggests that the Oldest Old are at greater risk of social exclusion, and that the effect of age persists over and above the effect of the other predictors analysed in these models.

\section{Discussion}

As people in western nations are living longer, it is now necessary to differentiate the Oldest Old from what could be termed the 'younger old' (aged sixty-five to eighty-four). This article has looked at whether people aged eighty-five-and-over are at greater risk of social exclusion than the younger old. It used the definition of social exclusion adopted in the 1999 Poverty and Social Exclusion Survey and applied by Patsios (2000), focusing specifically on service access and social contact.

Our analysis found that the Oldest Old are at greater risk of experiencing both types of social exclusion compared to the sixty-five to eighty-four age group. Previous research has found that heightened risk of social detachment among the over-80s is explained by whether or not they live alone (Tomaszewski and Barnes, 2008). Our analysis shows that the age effect in determining people's risk of social exclusion persists even when living alone is taken into account. This is evidence that the Oldest Old are at more severe risk of social exclusion. One could attribute this to declining health among this age group, yet the analysis shows that those aged eighty-five and above are still at greater risk of social exclusion once health is taken into account. Of course, it is possible that health exerts an indirect effect in that people aged eighty-five and above today are likely to have outlived most of their peers and therefore have diminished social networks. An alternative explanation is that economic factors lie behind the findings. As mentioned above, there are myriad complexities inherent in assessing the finances of the Oldest Old, from calculating asset wealth and other income, to accounting for unclaimed benefit entitlements and for care costs. These matters were beyond the scope of this article but should be subject to future research.

In light of our findings, we must note the evidence that a loss of social contact can damage physical and mental health (Social Exclusion Unit, 2005). Furthermore, older persons are more likely to need care from external providers if they live alone, which 
is more likely among the Oldest Old. This places more pressure on statutory health and social care services. Hospital bed-blocking by older patients who are unable to live independently is an ongoing strain on NHS resources and any viable solutions should be considered. Measures must be taken to help the Oldest Old to continue living in their own homes for as long as possible, whilst maintaining adequate social relations and being able to access services. As first steps, awareness and availability of technology such as Skype, telecare and online banking/shopping should be improved. This would be a useful step, bringing existing provision to those who currently remain excluded. It is quite reasonable to expect that the benefits of technology can be shared by all.

Third-sector provision such as Telephone Befriending Services and Dial-a-Ride community transport schemes have attempted to alleviate loneliness and isolation by connecting people to service outlets and facilitating social interaction, but such provision varies by geographical area. This can place it beyond the reach of people who have little contact with healthcare professionals who can refer them to such support. Voluntary organisations can play an important role in ensuring that an ageing society does not exclude older members of the population, but they cannot tackle the social exclusion of the Oldest Old alone. The government has a responsibility to ensure that the most vulnerable citizens are able to participate fully in social life within, and beyond, their home neighbourhoods. Even if the moral argument is not deemed sufficiently powerful, as life expectancy increases and the age profile of western nations pushes upward, the needs of future cohorts of the Oldest Old will become impossible to ignore.

\section{Note}

1 We ran models with three different health indicators (satisfaction with health, general health and whether health limits moderate activities). Our findings in relation to age remained statistically significant in all models across all three outcome variables.

\section{References}

Age, UK (2013) Improving Later Life: Understanding the Oldest Old, London: Age UK. Askham, J. (1992) Life After 60, London: Age Concern Institute of Gerontology.

Baltes, M. M. and Smith, J. (2003) 'New frontiers in the future of aging: from successful aging of the young old to the dilemma of the fourth age', Gerontology, 49, 2, 123-35.

Barnes, M., Blom, A., Cox, K. and Lessof, C. (2006) The Social Exclusion of Older People: Evidence from the First Wave of the English Longitudinal Study of Ageing, London: ODPM.

Burchardt, T. (2000) 'Social exclusion: concepts and evidence', in D. Gordon and P. Townsend (eds.), Breadline Europe: The Measurement of Poverty, Bristol: Policy Press.

Burchardt, T., Le Grand, J. and Piachaud, D. (2002) 'Degrees of exclusion: developing a dynamic multidimensional measure', in J. Hills, J. Le Grand and D. Piachaud (eds.), Understanding Social Exclusion, Oxford: Oxford University Press, 30-43.

Byrne, D. (1999) Social Exclusion, Buckingham: Open University Press.

Collins, J., Holman, A., Aspis, S. and Amor, Y. (1997) Living Well into Old Age, York: Joseph Rowntree Foundation.

Commins, P. (1993) Combating Exclusion in Ireland 1990-1994, a Midway Report, Brussels: European Commission.

Cracknell, R. (2010) 'The ageing population', in Key Issues for the New Parliament 2010, London: House of Commons Library Research.

Davey, J. A. (2007) 'Older people and transport: coping without a car', Ageing and Society, 27, 1, 49-65. 
Del Bono, E., Sala, E., Hancock, R., Gunnell, C. and Parisi, L. (2007) 'Gender, older people and social exclusion: a gendered review and secondary analysis of the data', ISER Working Paper 2007-13, University of Essex.

Department for Transport, Local Government and the Regions (DTLR) (2001) Focus on Personal Travel, London, The Stationery Office.

Dini, E. and Goldring, S. (2008) 'Estimating the changing population of the oldest old', Population Trends, $132,2,8-16$.

Gilleard, C. and Higgs, P. (2010) 'Ageing without agency: theorizing the fourth age', Aging and Mental Health, 14, 2, 121-8.

Gilleard, C. and Higgs, P. (2011) 'Frailty, disability and old age: a re-appraisal', Health, 15, 5, 475-90.

Gjonça, E., Stafford, M., Zaninotto, P., Nazroo, J. and Wood, N. (2010) 'Health and social engagement among the oldest old', in J. Banks, C. Lessof, J. Nazroo, N. Rogers, M. Stafford and A. Steptoe (eds.), Financial Circumstances, Health and Well-being of the Older Population in England: ELSA 2008 (Wave 4), London: Institute for Fiscal Studies, 227-53.

Gordon, D., Adelman, L., Ashworth, K., Bradshaw, J., Levitas, R., Middleton, S., Pantazis, C., Patsios, D., Payne, S., Townsend, P. and Williams, J. (2000) Poverty and Social Exclusion in Britain, York: Joseph Rowntree Foundation.

Harman, H. (1997) 'Speech at the launch of the Centre for Analysis of Social Exclusion', 12 November, London School of Eonomics, Press release, Department of Social Security, London.

Heikkinen, R. L. (2000) 'Ageing in an autobiographical context', Ageing and Society, 20, 4, 467-83.

Her Majesty's Government (2013) Government Response to the House of Lords Select Committee on Public Service and Demographic Change Report of Session 2012-13: Ready for Ageing? Cm 8677, London: The Stationery Office.

House of Lords (2013) Ready for Ageing? Select Committee on Public Service and Demographic Change, Report of Session 2012-13, HL Paper 140, London: The Stationery Office.

ILC-UK (2013) Understanding the Oldest Old, London: ILC-UK.

Kenyon, S., Rafferty, J. and Lyons, G. (2003) 'Social exclusion and transport in the UK: a role for virtual accessibility in the alleviation of mobility-related social exclusion?', Journal of Social Policy, 32, 3, 317-38.

Key, W. (2014) 'Ageing in rural communities: from "idyll" to "exclusion"?', in G. Bosworth and P. Somerville (eds.), Interpreting Rurality, London: Routledge, 251-66.

Kneale, D. (2012) Is Social Exclusion Still Important for Older People? London: ILC-UK.

Levitas, R. (1998) The Inclusive Society? Social Exclusion and New Labour, Basingstoke: Macmillan.

Levitas, R., Pantazis, C., Fahmy, E., Gordon, D., Lloyd, E. and Patsios, D. (2007) The Multi-Dimensional Analysis of Social Exclusion, Bristol: Townsend Centre for the International Study of Poverty and Bristol Institute for Public Affairs.

Lister, R. (1997) Citizenship: Feminist Perspectives, Basingstoke: Macmillan.

Lloyd, L., Calnan, M., Cameron, A., Seymour, J. and Smith, R. (2014) 'Identity in the fourth age: perseverance, adaptation and maintaining dignity', Ageing and Society, 34, 1, 1-19.

Millar, J. (2003) 'Gender, poverty and social exclusion', Social Policy and Society, 2, 3, 181-8.

ONS (2003) Census 2001: National Report for England and Wales, London: The Stationery Office.

ONS (2013) 'What does the 2011 Census tell us about the "oldest old" living in England \& Wales'? Office for National Statistics, http://webarchive.nationalarchives.gov.uk/20160105160709/ http://www.ons.gov.uk/ons/dcp171776_342117.pdf [accessed 1.7.2014].

ONS (2015) 'National Population Projections: 2014-based Statistical Bulletin', https:/www.ons.gov.uk/ peoplepopulationandcommunity/populationandmigration/populationprojections/bulletins/ nationalpopulationprojections/2015-10-29 [accessed 1.7.2016].

Patsios, D. (2000) Poverty and Social Exclusion amongst the Elderly, Working Paper 20, Bristol: Townsend Centre for International Poverty Research.

Pickard, L. (2015) 'A growing care gap? The supply of unpaid care for older people by their adult children in England to 2032', Ageing and Society, 35, 1, 96-123. 
Pickard, L., Wittenberg, R., Comas-Herrera, A., King, D. and Malley, J. (2007) 'Care by spouses, care by children: projections of informal care for older people in England to 2031', Social Policy and Society, $6,3,353-66$.

Poon, L. W. and Cohen-Mansfield, J. (2011) (eds.) Understanding Well-Being in the Oldest Old, Cambridge: Cambridge University Press.

Public Health England (2016) Recent Trends in Life Expectancy at Older Ages: Update to 2014, London: Public Health England.

Rice, N. E., Lang, I. A., Henley, W. and Melzer, D. (2010) 'Baby boomers nearing retirement: the healthiest generation?', Rejuvenation Research, 13, 1, 105-14.

Room, G. (1995) 'Conclusions', in G. Room (ed.), Beyond the Threshold - the Measurement and Analysis of Social Exclusion, Bristol: Policy Press, 233-47.

Scharf, T., Phillipson, C., Kingston, P. and Smith, A. (2002) Growing Older in Socially Deprived Areas: Social Exclusion in Later Life, London: Help the Aged.

Serra, V., Watson, J., Sinclair, D. and Kneale, D. (2011) Living Beyond 100: A Report on Centenarians, London: ILC-UK.

Shergold, I. and Parkhurst, G. (2012) 'Transport-related social exclusion amongst older people in rural Southwest England and Wales', Journal of Rural Studies, 28, 8, 412-21.

Social Exclusion Unit (2005) Excluded Older People, Social Exclusion Unit Interim Report, London: Social Exclusion Unit.

Social Exclusion Unit (2006) A Sure Start to Later Life: Ending Inequalities for Older People, A Social Exclusion Unit Final Report, London: Social Exclusion Unit.

Tomassini, C. (2005) 'The demographic characteristics of the oldest old in the United Kingdom', Population Trends, 120, 15-22.

Tomassini, C. (2006) 'The oldest old in Great Britain: change over the last 20 years', Population Trends, 123, 32-9.

Tomaszewski, W. and Barnes, M. (2008) 'Investigating the dynamics of social detachment in older age', in J. Banks, E. Breeze, C. Lessof and J. Nazroo (eds.), Living in the 21st Century: Older People in England, The 2006 English Longitudinal Study of Ageing (Wave 3), London: Institute for Fiscal Studies, 150-85.

University of Essex (2010) British Household Panel Survey: Waves 1-18, 1991-2009, 7th edn, UK Data Service, SN: 5151, Institute for Social and Economic Research, University of Essex, http://dx.doi.org/10.5255/UKDA-SN-5151-1.

University of Essex (2015) Understanding Society: Waves 1-5, 2009-2014, 7th edn, UK Data Service, SN: 6614, Institute for Social and Economic Research, University of Essex, http://dx.doi.org/10.5255/UKDA-SN-6614-7.

Veit-Wilson, J. (2002) 'Researching poverty and the poor', Journal of Social Policy, 31, 3, 537-44.

Victor, C., Bond, J., Bowling, A. and Scambler, S. (2003) Loneliness, Social Isolation and Living Alone in Later Life, Research Findings 17, Sheffield: ESRC Growing Older Programme.

Walker, A. (1997) 'Introduction', in A. Walker and C. Walker (eds.), Britain Divided: The Growth of Social Exclusion in the 1980s and 1990s, London: CPAG.

Walker, A. (2000) 'Poverty and inequality in old age', in J. Bond, P. Coleman and S. Peace (eds.), Ageing in Society: An Introduction to Social Gerontology, 2nd edn, London: Sage. 